\title{
Interhemispheric transcallosal approach for resection of intraventricular central neurocytoma
}

\author{
JAMES K. LiU, M.D. \\ Departments of Neurological Surgery and Otolaryngology-Head and Neck Surgery, Center for Skull Base and \\ Pituitary Surgery, Neurological Institute of New Jersey, University of Medicine and Dentistry of New Jersey, New \\ Jersey Medical School, Newark, New Jersey
}

\begin{abstract}
The interhemispheric transcallosal approach is a versatile approach to access intraventricular tumors of the lateral and third ventricles. The advantages of using a transcallosal approach over a classical transcortical approach include a direct midline orientation with symmetrical access to both lateral ventricles and both walls of the third ventricle. In addition, violation of the cerebral cortex and the risk of postoperative seizures can be avoided. Central neurocytomas are rare benign tumors that represent approximately 0.1 to $0.5 \%$ of all primary brain tumors. They are typically located in the lateral ventricles and tend to present clinically with hydrocephalus. Currently, surgical removal with a gross-total resection is the treatment of choice. In this operative video manuscript, the author demonstrates an illustrative step-by-step technique for microsurgical resection of a large central neurocytoma involving both lateral ventricles in a patient with hydrocephalus using the interhemispheric transcallosal approach. A complete removal was performed without the need for permanent shunting. The operative technique and surgical nuances, including the surgical approach, intraventricular tumor removal, and closure are illustrated in this video atlas.

The video can be found here: http://youtu.be/KzC8QYsTKeg.

(http://thejns.org/doi/abs/10.3171/2013.V1.FOCUS12353)
\end{abstract}

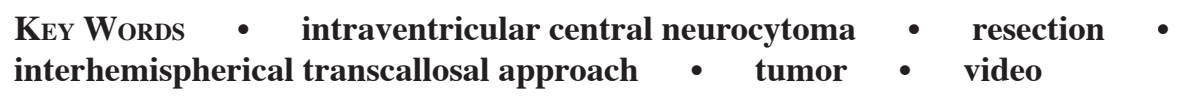

Manuscript submitted October 24, 2012.

Accepted November 2, 2012.

Please include this information when citing this paper: DOI: 10.3171/2013.V1.FOCUS12353.

Address correspondence to: James K. Liu, M.D., Department of Neurological Surgery, University of Medicine and Dentistry of New Jersey, New Jersey Medical School, 90 Bergen Street, Suite 8100, Newark, New Jersey 07101. email: james.liu@umdnj.edu. 